Esta revista forma parte del acervo de la Biblioteca Jurídica Virtual del Instituto de Investigaciones Jurídicas de la UNAM

\title{
Evaluación integral del modelo de acceso a radio y televisión en materia electoral
}

\section{Jorge Alcocer Villanueva*}

\section{Sumario:}

I. Marco jurídico

II. Interpretación judicial de las normas reguladoras del modelo de acceso a radio y televisión en materia electoral (estudio de sentencias relevantes y jurisprudencia del TEPJF)

III. Sistema integral de administración de los tiempos del Estado

IV. Entrevistas realizadas a actores clave en el diseño e implementación de la reforma electoral de 2007-2008 en materia de radio y televisión

V. La polémica en torno a la reforma

* Licenciado y maestro en Economía por la UNAM; actualmente es coordinador general del Centro de Estudios para un Proyecto Nacional Alternativo, S. C. (CEPNA), y director general de la revista mensual Voz y Voto. 
Esta revista forma parte del acervo de la Biblioteca Jurídica Virtual del Instituto de Investigaciones Jurídicas de la UNAM www.juridicas.unam.mx

\section{Resumen:}

El artículo que se presenta está basado en el informe de observación electoral que el CEPNA elaboró para el PNUD, producto del esfuerzo de estudio y análisis desarrollado desde la aprobación y promulgación de la reforma electoral de 2007-2008, aunque su objetivo principal ha sido la evaluación del modelo de acceso a radio y televisión durante los procesos electorales que tuvieron lugar desde finales de 2011 hasta la jornada del 1o. de julio de 2012.

Se detallan las disposiciones constitucionales, legales, reglamentarias, acuerdos y sentencias en materia de acceso a radio y televisión con fines electorales. Se analizan los principales criterios de la Sala Superior del TEPJF sobre diversos temas: administración de tiempos del Estado en radio y televisión por parte del IFE, procedimientos sancionadores especiales, difusión de actividades de los servidores públicos, realización y difusión en medios electrónicos de los debates de precandidatos y candidatos presidenciales, suspensión de la propaganda gubernamental; también aspectos del Sistema integral de administración de los tiempos del Estado, y resultados de las entrevistas realizadas a legisladores y dirigentes partidistas sobre el tema de radio y televisión, entre otros.

Palabras clave: modelo de acceso a radio y televisión, tiempos del Estado, reforma electoral, monitoreo, Sistema Integral de Administración de los Tiempos del Estado, libertad de expresión. 


\section{Marco jurídico}

Las normas constitucionales, legales y reglamentarias, los acuerdos relativos a los procedimientos especiales sancionadores, así como las sentencias del Tribunal Electoral del Poder Judicial de la Federación (TEPJF) en los juicios relativos al modelo, constituyeron el primer ámbito de atención del estudio. Para tal fin, la investigación se organizó conforme al esquema presentado al PNUD en abril de 2012.

En primera instancia, y de manera interrelacionada, se estudiaron las normas del artículo 41 de la Constitución Política de los Estados Unidos Mexicanos (CPEUM), en particular lo relativo al acceso a radio y televisión, así como su desarrollo en la ley secundaria, es decir, en el Código Federal de Instituciones y Procedimientos Electorales (Cofipe), con el objetivo de establecer su idoneidad en una elección de ámbito general, como la celebrada en 2011-2012, así como en su aplicación en los procesos electorales locales concurrentes celebrados en ese mismo periodo.

Con base en fuentes de naturaleza legislativa y para entender el sentido de las normas, es imprescindible remitirse a las iniciativas de reforma que les dieron origen, a los dictámenes aprobados en las comisiones del Congreso y, finalmente, al debate en el pleno de cada Cámara. Asimismo, se tomaron en cuenta diversos ensayos de análisis de la normatividad electoral aprobada entre 2007 y 2008 que han publicado juristas y especialistas en materia electoral, así como las sentencias que el pleno de la Suprema Corte de Justicia de la Nación (SCJN) emitió con motivo de las impugnaciones de que fueron objeto tanto la reforma constitucional como la del Cofipe.

En lo que hace al texto constitucional (artículo 41), el estudio tuvo como principal propósito determinar si las normas relativas al modelo de acceso a radio y televisión con fines electorales guardan congruencia interna, permitieron su desarrollo en la ley secundaria (Cofipe) y posibilitaron la eficaz administración de los tiempos del Estado en dichos medios durante los procesos electorales celebrados desde su promulgación, con especial atención en la experiencia cursada en el proceso electoral federal de 2011-2012 y en los procesos locales concurrentes. 
Esta revista forma parte del acervo de la Biblioteca Jurídica Virtual del Instituto de Investigaciones Jurídicas de la UNAM

El poder reformador de la Constitución decidió establecer en el texto de la carta magna una regulación detallada para el nuevo modelo de acceso a radio y televisión. Bajo el principio de que lo "escrito en la Constitución no puede ser inconstitucional", en 2007 se decidió introducir en la base III del artículo 41 de la carta magna, normas tan detalladas como la relativa a los minutos que estarían a disposición del Instituto Federal Electoral (IFE) para fines electorales, y su forma de distribución entre partidos políticos y autoridades electorales, para las diferentes etapas de los procesos comiciales. Fue una solución "heterodoxa" para muchos juristas, pero acertada para quienes consideran que esa fue la mejor manera de "blindar" el modelo.

Es dable afirmar que en la historia constitucional de México, desde la promulgación y entrada en vigor de la Constitución de 1917, ninguna reforma ha suscitado tantas polémicas e impugnaciones como las que motivó el texto del artículo 41 promulgado en noviembre de 2007. Fue provechoso que se produjeran tales cuestionamientos, sobre todo porque tocaron un asunto crucial: la libertad de expresión. Los impugnadores de la reforma sostuvieron que había una "grave vulneración de la libertad de expresión", ya que el texto constitucional prohíbe a cualquier persona comprar tiempo en radio y televisión con fines de propaganda electoral. Ese fue el asunto toral de la querella en los medios, y también ante los jueces constitucionales.

Si bien la polémica prosigue, e incluso algunos ciudadanos han acudido ante la Corte Interamericana de Derechos Humanos (Corte IDH) para impugnar las normas referidas, lo cierto es que ahora hay una verdad jurídica, determinada por el pleno de la Suprema Corte, en el sentido de que no hay tal vulneración a la libertad de expresión, esa sentencia dotó al texto constitucional bajo estudio de una fortaleza que es la mejor base para su continuidad, fortalecimiento y consolidación. Al sostener lo anterior, no es la pretensión negar los errores y omisiones del texto del artículo 41 constitucional que el estudio encuentra y reporta, sino solamente dejar sentado que su eventual cambio tendría que obedecer, creemos, al claro propósito de fortalecer y consolidar lo ya alcanzado, al mismo tiempo que se corrijan efectos imprevistos y no deseados, en especial el fenómeno conocido como "spotización" que la ley secundaria (Cofipe) y las disposiciones reglamentarias emitidas por el Consejo General del IFE agravaron.

Para hacer posible, con una base constitucional, la modificación del uso de los tiempos del Estado por los partidos políticos, y con el fin de 
Esta revista forma parte del acervo de la Biblioteca Jurídica Virtual del Instituto de Investigaciones Jurídicas de la UNAM

superar ese negativo fenómeno, la reforma del artículo 41 sería deseable, siempre y cuando no sea el pretexto para dar paso a cambios que impliquen una abierta contrarreforma, como el regreso a la situación previa a 2007. Debido a esa prevención, se expone la opción de una reforma en el Cofipe para atender y corregir la llamada "spotización", pues nuestra conclusión en cuanto a las normas constitucionales estudiadas, es que la experiencia (2008-2012) ha acreditado su pertinencia, solidez y eficacia. A ello contribuyeron las sentencias del pleno de la SCJN y las interpretaciones emitidas, en varias de sus sentencias, por la Sala Superior del TEPJF. Los mayores problemas que nuestro estudio encontró en la normatividad legal, y que afectan negativamente la operación del modelo, están ubicados en el Cofipe.

Uno de los mayores hallazgos de nuestro estudio es la posibilidad, jurídica y operativa, de introducir cambios radicales en el formato (minutos de duración) de los mensajes en radio y televisión de partidos políticos y autoridades electorales, sin que eso requiera reformar la Constitución. Para tal propósito, como se explica, sería necesario establecer en el Cofipe la existencia y obligada utilización por los partidos políticos de mensajes de entre tres y cinco minutos continuos, en que los candidatos, ya sean presidenciales o al Congreso, expongan sus propuestas programáticas. Para tal propósito, la norma legal establecería la compactación de los minutos finales de cada hora con los primeros de la hora inmediata siguiente, tal como han venido haciendo los concesionarios y permisionarios desde 2009, con la validación de la Sala Superior del TEPJF.

En lo relativo al IFE, se exploran diversas opciones para corregir el indeseado efecto que produce la interpretación reglamentaria por la cual sólo el Instituto, y por su conducto otras autoridades electorales, puede utilizar el tiempo de radio y televisión no asignado a los partidos políticos durante los procesos electorales. Aun cuando esa interpretación se mantuviera, es conveniente sustentarla desde la norma legal, así como explorar el uso del tiempo de autoridades electorales en formatos diferentes a los mensajes de 30 segundos, que agudizan la saturación de radioescuchas y televidentes y, durante la etapa de precampañas, opacan los mensajes emitidos por los partidos políticos.

En lo que se refiere al ámbito reglamentario, se sostiene que es la necesidad de que el Poder Legislativo lleve a la ley, o corrija, las disposiciones sustantivas que el Consejo General del IFE introdujo en el Reglamento de Acceso a Radio y Televisión y en otros acuerdos o 
Esta revista forma parte del acervo de la Biblioteca Jurídica Virtual del Instituto de Investigaciones Jurídicas de la UNAM

lineamientos en la misma materia, ya fuera para subsanar omisiones legislativas, o para interpretar las normas legales cuando, a su juicio, éstas son confusas o insuficientes. La cuestión desborda los límites de nuestro estudio, pero es evidente que en materia reglamentaria, desde hace varios años y en múltiples cuestiones, el Consejo General del IFE ha venido incurriendo en la indebida práctica de suplir, corregir o subsanar temas y asuntos en que los legisladores, por acción u omisión, pusieron límites a las autoridades electorales.

Para el fortalecimiento y consolidación del modelo de acceso a radio y televisión es recomendable que todos sus aspectos sustantivos queden establecidos en el Cofipe, de tal forma que la facultad reglamentaria del Consejo General del IFE se circunscriba a establecer el modo y tiempo en que la norma legal será cumplida.

En lo que se refiere al análisis de los procedimientos especiales sancionadores relativos a radio y televisión (2011-2012), encontramos que la causa más frecuente para su interposición se refiere al contenido de los mensajes partidistas, en relación con la norma constitucional y del Cofipe que obliga a los partidos políticos a abstenerse, en su propaganda política o electoral (de cualquier tipo), de expresiones que denigren a las instituciones y a los propios partidos, o que calumnien a las personas. La primera parte de la norma constitucional ("denigrar") ha dado lugar al abuso en la presentación de quejas partidistas, que deben ser resueltas con las normas y tiempos del procedimiento especial sancionador y que, en la mayoría de los casos, conducen a juicios ante la Sala Superior del TEPJF. Por tal motivo, diversos especialistas han propuesto suprimir esa parte de la norma legal y dejar solamente la protección a las personas, en el sentido de sancionar la calumnia. Otras voces se pronuncian por establecer criterios legales detallados para ambas previsiones (denigración y calumnia), de tal forma que se reduzca el margen de discrecionalidad con el que han venido resolviendo este asunto tanto los consejeros electorales del IFE como los magistrados de la Sala Superior del TEPJF.

En cuanto a la pertinencia de trasladar a las salas regionales y Superior del TEPJF las facultades que hoy tiene el IFE en materia de procedimientos sancionadores, nuestra conclusión es que ello ocasionaría mayores problemas y conflictos, al otorgar a la autoridad jurisdiccional facultades de naturaleza administrativa y al propiciar la inevitable judicialización de todas las quejas por violaciones administrativas al marco legal electoral. 


\section{La interpretación judicial de las normas reguladoras del modelo de acceso a radio y televisión en materia electoral (estudio de sentencias relevantes y jurisprudencia del TEPJF)}

En este apartado se exponen los resultados del análisis de los principales criterios establecidos por la Sala Superior del TEPJF en materia de administración de los tiempos del Estado en radio y televisión por el IFE y en lo relativo al acceso de partidos políticos y autoridades electorales a dichos tiempos.

En el sistema electoral mexicano, desde la reforma de 1996 el Tribunal Electoral fue dotado de facultades amplísimas con el fin de "garantizar los principios de constitucionalidad y legalidad de los actos y resoluciones electorales". En uso de esas facultades, el TEPJF, especialmente su Sala Superior, ha realizado tanto el control de constitucionalidad sobre los actos y resoluciones del IFE y de otras autoridades, en lo que hace a la operación del modelo de acceso a radio y televisión en materia político-electoral, como la interpretación de diversas normas legales, e incluso constitucionales, cuando lo consideró necesario para despejar dudas sobre la norma, o para suplir deficiencias u omisiones de la ley.

En general, de nuestro estudio se desprende que las sentencias, tesis y jurisprudencia emitidas por la Sala Superior del TEPJF han sido positivas para la adecuada instrumentación del modelo y han fortalecido las capacidades del IFE en este ámbito. Sobre el particular, baste citar los criterios sostenidos sobre el carácter del IFE como autoridad única para administrar los tiempos del Estado en radio y televisión con fines electorales; los límites de la facultad reglamentaria del Consejo General del IFE, que en ningún caso puede ir más allá ni contrariar el sentido de la legislación que se pretende reglamentar; la distribución de competencias entre el IFE y las autoridades locales para la imposición de sanciones administrativas por infracciones cometidas en radio y televisión; la prohibición de adquirir o contratar tiempos en radio y televisión con fines de propaganda político-electoral, la cual no implica la transgresión a las libertades constitucionales de expresión, información y comercial; la necesaria distinción entre censura previa y la exclusión de mensajes y programas ilícitos por parte de los concesionarios y permisionarios; la obligación que todos los concesionarios y 
Esta revista forma parte del acervo de la Biblioteca Jurídica Virtual del Instituto de Investigaciones Jurídicas de la UNAM

permisionarios de radio y televisión tienen de transmitir las pautas de propaganda electoral, con independencia de su naturaleza o del tipo de programación que transmitan, entre otros.

Sin embargo, en algunos casos la Sala Superior del TEPJF, con el propósito de integrar o de colmar supuestas o reales lagunas u omisiones de la ley, ha incurrido en interpretaciones que se apartan tanto de la letra de la norma, como de la intención que subyace en su aprobación por el Poder Legislativo federal. Tal es el caso de la interpretación que la Sala Superior decidió para la aplicación de los procedimientos sancionadores especiales fuera de los periodos electorales; para la asignación de tiempo de radio y televisión a las autoridades electorales locales y a los partidos políticos locales, y de las contradictorias sentencias relativas a la aplicación de medidas cautelares para la suspensión de mensajes de partidos políticos en radio y televisión.

En un tema en que el Tribunal parece haber abandonado su papel de garante de la Constitución y la ley, la Sala Superior consideró que la difusión de los informes de actividades de los servidores públicos a través de promocionales en radio y televisión no constituye una infracción legal, cuando se trata de informes de los legisladores federales (caso del Partido Verde Ecologista de México), a través de promocionales de radio y televisión, fuera de los periodos de precampañas y campañas electorales, pues al no constituir propaganda electoral, según el Tribunal, es una conducta lícita. Cabe dejar asentado que, conforme a la evaluación de la aplicación del modelo de acceso a radio y televisión, que es objeto de este estudio, las sentencias del TEPJF a que hemos aludido no tuvieron mayor impacto en ese ámbito, aunque sí ocasionaron polémicas y debates a lo largo del proceso electoral de 2011-2012.

Así sucedió con las sentencias relativas a la realización y difusión en los medios electrónicos de los debates entre precandidatos y candidatos presidenciales, y otros candidatos a diversos cargos de representación popular, caso en que las contradictorias sentencias de la Sala Superior dieron pie a una nueva campaña mediática contra la reforma electoral de 2007-2008, particularmente, contra las reglas de operación del modelo. Con el fin de evitar la repetición de polémicas estériles, es conveniente que el Poder Legislativo federal deje establecidos en la ley los criterios rectores a que deberá sujetarse la realización y difusión en radio y televisión de debates diferentes a los que ya regula el Cofipe. 
Esta revista forma parte del acervo de la Biblioteca Jurídica Virtual del Instituto de Investigaciones Jurídicas de la UNAM

En lo que concierne a la suspensión de la propaganda gubernamental en las campañas electorales, la Sala Superior del TEPJF enmendó su criterio original, establecido a través de jurisprudencia, en el sentido de que tal suspensión debía ocurrir desde el inicio de las precampañas; esa interpretación contrariaba flagrantemente la norma constitucional que determina el plazo durante el cual no se podrá difundir esa propaganda, que comprende desde el inicio de las campañas hasta la conclusión de la jornada electoral, por lo que la Sala Superior debió dejar sin efecto la mencionada jurisprudencia.

Un aspecto también opinable es la amplitud de criterio con el que las autoridades electorales, administrativa y jurisdiccional, han establecido excepciones a la prohibición de difundir propaganda gubernamental durante las campañas electorales, que en rigor debe constreñirse a la información de las propias autoridades electorales, servicios educativos y de salud, o las necesarias para la protección civil en casos de emergencia. En este sentido el TEPJF ha sostenido que, durante las campañas, es lícita la difusión de propaganda de una serie de entes gubernamentales que nada tienen que ver con las materias exceptuadas en la Constitución, en virtud de laxas interpretaciones de los conceptos de educación y salud.

En una primera conclusión, cabe resaltar la heterogeneidad de criterios de las autoridades electorales, tanto del IFE como del TEPJF, en este asunto, como la proliferación de solicitudes de excepción interpuestas por las dependencias del gobierno federal, en abierta intención de cometer fraude a la ley, como terminó sucediendo. En todo caso, la experiencia jurisdiccional cursada en el proceso electoral de 2011-2012 entrega un valioso acervo de criterios interpretativos que deberán tomarse en cuenta para futuras modificaciones a la normatividad constitucional y legal por las instancias competentes.

Como corolario de lo expuesto consideramos necesario establecer en la norma legal los criterios y reglas que regirán en el futuro aquellos asuntos de acceso a radio y televisión en que se ha acreditado defecto u omisión; ello redundará en un mejor desempeño de las autoridades electorales y en una mayor certeza para los partidos políticos, sus candidatos, los demás sujetos regulados y la sociedad en general. 
Esta revista forma parte del acervo de la Biblioteca Jurídica Virtual del Instituto de Investigaciones Jurídicas de la UNAM

\section{Sistema Integral de Administración de los Tiempos del Estado (SIATE)}

\section{Verificación}

El SIATE consiste en un sistema de procedimientos y tecnología usados para digitalizar, almacenar, realizar búsquedas, enviar a cualquier usuario los materiales y archivos que se le solicitan; editar, calificar y catalogar los promocionales (mensajes de radio y televisión) que son entregados a las áreas responsables del IFE, además de comprobar la correcta transmisión y entrada al aire, conforme a las pautas previamente aprobadas, de los promocionales de audio y video. Para tales fines, el SIATE cuenta con cuatro subsistemas estratégicos: el subsistema de ingesta y catalogación de materiales, el subsistema de pautas, el subsistema de transmisión de materiales, y el subsistema de verificación y monitoreo. La infraestructura tecnológica definida para el SIATE está concebida para la generación de pautas de radio y televisión y la vinculación con cada uno de los espacios a que tienen derecho tanto los partidos políticos como las autoridades electorales en cada una de las estaciones de radio y canales de televisión del país. Además, se encarga de seleccionar los receptores para recibir y grabar material y así enviarles los promocionales por satélite o por Internet. A través del Centro Nacional de Control y Monitoreo (Cenacom), que tiene como funciones la generación y distribución de huellas acústicas, la interconexión, distribución y consolidación de datos, con acceso a grabaciones de radio y televisión, se distribuye a los Centros de Verificación y Monitoreo (Cevem) toda la información correspondiente a las pautas y huellas acústicas generadas, con la finalidad de detectar, sistematizar, integrar reportes sobre los promocionales, comparar la pauta notificada con la transmitida y elaborar tablas y gráficas de la información.

Durante el proceso electoral de 2011-2012, en ningún momento el Sistema se vio comprometido por volumen de trabajo, ya que el número de promocionales para calificación técnica llegó, tan solo, a 4200 hasta el 18 de junio de 2012, fecha en que se cumplió la última entrega de materiales audiovisuales para su envío a los concesionarios y permisionarios de radio y televisión. Lo anterior significó que nunca se 
Esta revista forma parte del acervo de la Biblioteca Jurídica Virtual del Instituto de Investigaciones Jurídicas de la UNAM

rebasó la capacidad máxima de análisis, que es de 200 promocionales por día, lo que da cuenta del exceso de capacidad instalada en el Sistema. Los resultados señalan que el SIATE tuvo la capacidad de verificar un $97 \%$ de los promocionales pautados, y de reprogramar el resto para dar cumplimiento cabal a lo pautado. Las principales preocupaciones residen, primero, en el formato de spot, que hasta ahora ha sido el único modo de mensaje tanto de los partidos como de las autoridades electorales, sin abrir espacio a nuevos formatos de comunicación, y segundo, en la apropiación excesiva del tiempo de Estado que el IFE destina a sus propios fines y a los de otras autoridades comiciales. En todo caso, la consolidación del modelo de comunicación político-electoral supondrá, necesariamente, un análisis del SIATE y su utilización más allá de procesos electorales. En total el IFE pautó 43.7 millones de promocionales en el proceso electoral federal de 2011-2012, de éstos, $51 \%$ correspondió a los partidos políticos y el resto, a las autoridades electorales. A los partidos políticos en el ámbito federal les correspondió $88 \%$ del tiempo disponible para los partidos, mientras que las autoridades federales dispusieron del $79 \%$ del tiempo correspondiente a las autoridades.

Tabla 1

Promocionales pautados por el IFE en el proceso electoral de 2011-2012

\begin{tabular}{|c|c|c|c|c|c|}
\hline \multirow{2}{*}{ Etapa } & \multicolumn{2}{|c|}{ Partidos } & \multicolumn{2}{c|}{ Autoridades } & \multirow{2}{*}{ Total } \\
\cline { 2 - 5 } & Federales & Locales & Federales & Locales & \\
\hline Precampañas & 4779157 & 250634 & 6568141 & 1746915 & 13344847 \\
\hline Intercampañas & 0 & 387419 & 7175327 & 1980947 & 9543693 \\
\hline Campañas & 15061774 & 1994049 & 2353406 & 571506 & 19980735 \\
\hline Veda & 0 & 0 & 686165 & 201053 & 887218 \\
\hline Total & 19840931 & 2632102 & 16783039 & 4500421 & 43756493 \\
\hline
\end{tabular}

Fuente: elaboración propia a partir de IFE.

Es indudable que se trata de un número abultado de spots, más de 43 millones, lo que si bien facilita el contacto de la ciudadanía con el proceso electoral, también puede generar rendimientos decrecientes o negativos, dada la cantidad de mensajes. 
Esta revista forma parte del acervo de la Biblioteca Jurídica Virtual del Instituto de Investigaciones Jurídicas de la UNAM

Asimismo, un pautado de varios miles de mensajes para más de 2300 emisoras de radio y televisión en el país genera, de forma natural, sobrecargas de un procedimiento que podría volverse más eficiente con un modelo menos concentrado en los promocionales y más proclive a otro tipo de contenidos. Debe reconocerse en primer lugar la capacidad institucional del IFE para cumplir con puntualidad una tarea compleja que operó en tiempos fatales. Una de las complicaciones del pautado surge de la existencia de calendarios diferentes en lo que toca a los periodos de precampaña, intercampaña y campaña entre las entidades que tienen procesos electorales locales y la federación. La positiva concurrencia entre fechas de elección debería ser fortalecida con la plena sincronía entre los calendarios electorales, federales y locales, cuando estos últimos son concurrentes.

Por otra parte, el IFE otorga tiempo a las autoridades electorales locales para acceder a la radio y la televisión con independencia de si hay proceso electoral local o no. Es un contrasentido que deberá corregirse en la legislación. En la misma dirección, ha de definirse si tiene sentido que durante los procesos electorales todo el tiempo del Estado corresponda al IFE y a los partidos, como ha interpretado el propio Instituto, o si éste es el administrador del tiempo del Estado y dentro de los 48 minutos diarios pueden insertarse, por ejemplo, las campañas educativas o de salud.

La operación del pautado muestra una alta complejidad que fue adecuadamente desarrollada por el IFE, complejidad que puede ser reducida con un nuevo modelo que, respetando el principio de no compra-venta de publicidad electoral, permita buscar un modelo de comunicación no basado en la "spotización".

Por otra parte, es necesario definir con mayor claridad cómo se distribuirá el tiempo del Estado entre las autoridades electorales y, finalmente, decidir si otros entes públicos pueden hacer uso de los 48 minutos que administra el IFE durante los procesos electorales.

\section{Uso de los spots}

Este punto se refiere a los resultados del análisis de contenidos de los mensajes de campaña que, en uso de sus prerrogativas de acceso a la radio y la televisión, enviaron los partidos políticos y coaliciones. 
De ese análisis se desprende que los partidos y coaliciones dedican el grueso de sus mensajes a las campañas presidenciales, en detrimento de la importancia de la elección para el Congreso de la Unión. Asimismo, se comprobó la continua presencia de las campañas de contraste o negativas, sobre las que se llegó a insistir con frecuencia, y sin fundamento, que estaban prohibidas a partir de 2007 en la legislación electoral mexicana. 1845000 spots, más de uno de cada diez (12\%) de los emitidos, fueron dirigidos por un partido o coalición contra otro partido o candidato. Las cifras examinadas también arrojan luz sobre el modelo de regulación de la comunicación político-electoral en nuestro país.

El acceso a los medios de comunicación en las campañas no depende ya de la capacidad económica de los partidos y de la disposición -o falta de ésta- de los concesionarios para transmitir los mensajes de los diferentes actores, lo cual es un principio que conviene preservar. Sin embargo, es evidente que hay un exceso de anuncios (14.5 millones sólo en campaña federal, a los que hay que agregar los de precampañas y procesos electorales locales) y que el modelo de spotización no resulta la mejor vía para promover un debate informado sobre los distintos proyectos políticos por los que puede optar la ciudadanía. Por ello, bien valdría explorar una fórmula que distribuya los tiempos del Estado para los partidos de otra manera: una franja reducida de spots, programas unitarios donde los partidos puedan desarrollar sus diagnósticos y propuestas, y más debates, no sólo presidenciales sino entre candidatos a diputados y senadores, precisamente porque los propios partidos atienden muy poco en su propaganda la elección de los legisladores y no se le confiere al Congreso la centralidad que tiene en la vida democrática del país.

\section{Bloqueos}

En todos los procesos electorales constitucionales que se celebran en México, los mensajes de los partidos políticos que se transmiten en radio y televisión son pautados por el IFE con cargo a los tiempos oficiales del Estado.

Para distinguir entre el mensaje de un partido para una elección federal y una local, o bien para saber a qué entidad federativa corresponde la difusión de un mensaje determinado de un partido, es nece- 
Esta revista forma parte del acervo de la Biblioteca Jurídica Virtual del Instituto de Investigaciones Jurídicas de la UNAM

sario que el IFE identifique a las estaciones de radio y canales de televisión en las diferentes entidades de la federación. Así, el IFE ha de tener una suerte de mapas de cobertura geográfica de las estaciones de radio y canales de televisión existentes en el país para enviar las pautas correspondientes a cada proceso electoral local.

En México es frecuente la existencia de "repetidoras", de concesiones locales, pertenecientes a consorcios de comunicación de mayor alcance nacional, que de hecho repiten la misma programación que se difunde desde la capital de la República, por ejemplo. Es necesario entonces que dichas repetidoras, a su vez, realicen un bloqueo de la señal ordinaria que reciben desde la capital del país para insertar las pautas del IFE que corresponden a las elecciones locales, o bien a candidaturas de mayoría relativa a las cámaras del Congreso de la Unión, que están asociadas a un territorio delimitado.

En esta cuestión, que fue objeto de controversia entre el IFE y los concesionarios de la televisión y dentro del propio Instituto, sobresale que no hubo ningún obstáculo al cumplimiento del bloqueo por parte de los concesionarios y permisionarios de radio en el país. En cambio, 157 estaciones de televisión, una vez iniciado el proceso electoral, intentaron eludir la obligación de practicar bloqueos a las señales nacionales para dar cumplimiento a las pautas locales. El IFE tomó diversos acuerdos para hacer viable la operación del bloqueo y el TEPJF respaldó la tesis de que no hay excepción al cumplimiento de las obligaciones constitucionales de emitir las pautas del IFE para los concesionarios y permisionarios. No obstante, y en concordancia con el IFE, permitió que esa obligación se retrasara en los casos en que hubiera imposibilidad técnica para el cumplimiento (157 emisoras televisivas en el proceso electoral de 2011-2012) hasta el 1o. de enero de 2013.

Ahora bien, es conveniente que el bloqueo se simplifique, lo cual puede operarse en dos campos simultáneamente:

a) Haciendo converger los plazos de las campañas, precampañas e intercampañas locales y federales, no sólo las fechas de las jornadas comiciales.

b) Superando el esquema del spot para que los partidos envíen sus mensajes a la ciudadanía. De esta manera, podría haber barras de información electoral, nacionales y locales, perfectamente identificables, en distintos horarios, para difundir la oferta de los actores políticos. 


\section{Monitoreo}

El monitoreo a noticieros de radio y televisión realizado por el IFE en el proceso electoral de 2011-2012 cumplió con las exigencias establecidas en la ley. En esta ocasión, con la colaboración de la Facultad de Ciencias Políticas y Sociales de la UNAM, el IFE cubrió el periodo de precampañas, del 18 de diciembre de 2011 al 15 de febrero de 2012, analizando 63 noticieros de radio y televisión; así como las campañas, del 30 de marzo al 27 de junio, abarcando 493 noticieros en todo el país. Para difundir los resultados del monitoreo se habilitó el sitio electrónico $w w w$. monitoreoifeunam.mx

Semana a semana, tanto en el periodo de precampaña como en el de campaña, la UNAM y el IFE dieron a conocer los hallazgos del monitoreo. Se trató de nueve informes durante el periodo de precampañas y de doce durante las campañas, así como un informe final tanto para la elección a la Presidencia de la República como de las dos elecciones al Congreso de la Unión (diputados y senadores).

En el caso del monitoreo durante el periodo de campañas, en el portal electrónico referido se pudo descargar la base de datos con toda la información del monitoreo. No obstante, ello no fue factible para el periodo de precampañas, diferencia que debería corregirse siguiendo el criterio de máxima publicidad de la información. Los resultados del monitoreo demuestran que los medios realizaron una labor de cobertura de las campañas caracterizada por la equidad en el tiempo y en el número de menciones dedicados a las distintas opciones políticas.

Esta situación, sin embargo, no es homogénea en el interior de las distintas entidades federativas. El tiempo que recibieron los distintos candidatos presidenciales se fue modificando a lo largo de la campaña electoral, para favorecer a los candidatos que aparecían en primer y segundo lugar en las encuestas electorales, lo que muestra que los medios son un reflejo de la actividad política y también influyen en ella. Por otra parte, el tiempo que los noticieros dedicaron a cubrir las actividades de los candidatos presidenciales contrasta de forma drástica con el dedicado a informar sobre los candidatos a cargos de representación en el Congreso de la Unión.

En México la cultura política y la información que reflejan los medios son sumamente presidencialistas, en demérito de la relevancia del Poder Legislativo. Asimismo, el grueso de la información política 
Esta revista forma parte del acervo de la Biblioteca Jurídica Virtual del Instituto de Investigaciones Jurídicas de la UNAM

se genera en noticieros que se emiten desde el Distrito Federal, con grandes asimetrías en lo que ocurre en los estados de la República, sobre todo en el caso de la televisión. El monitoreo que hace el IFE genera una enorme cantidad de información que no siempre ha sido explotada en su totalidad. Sería deseable que se promovieran foros políticos y académicos de análisis de los resultados del monitoreo, que eventualmente podrían generar ideas para el robustecimiento de este ejercicio.

En síntesis, el estudio de la operación técnica del modelo de acceso a radio y televisión para fines electorales comprueba su eficacia, medida a través del grado de cumplimiento de las pautas por los concesionarios y permisionarios, así como por el respeto de los partidos políticos y autoridades electorales a las disposiciones relativas a la entrega de materiales. Como se indica, la complejidad y costo de operación del SIATE y de sus subsistemas, así como su sobredimensionamiento durante los periodos no electorales, que ocasiona la subutilización de la capacidad instalada, son asuntos que deberán ser atendidos por las normas legales y mediante la exploración de usos alternativos del SIATE, que resulten compatibles y armónicos con su finalidad electoral.

A cinco años de la promulgación de las normas constitucionales y legales, el IFE cuenta hoy con la experiencia y capacidades para seguir operando el modelo. Los problemas de los que se ha dado cuenta son producto de las normas legales y reglamentarias, o bien de las interpretaciones que de las mismas hacen las autoridades electorales, no de los sistemas técnicos que posibilitan la administración y uso de los tiempos del Estado con fines electorales.

\section{Suspensión de propaganda gubernamental}

Si se toma literalmente la disposición constitucional del artículo 41, el cual establece que "las únicas excepciones" a la promoción de mensajes gubernamentales durante las campañas electorales "serán las campañas de información de las autoridades electorales, las relativas a servicios educativos y de salud, o las necesarias para la protección civil en casos de emergencia", y se contrasta con el Acuerdo del Consejo General del IFE en esta materia, de febrero de 2012, es evidente que la autoridad electoral administrativa asumió un criterio que se aparta de la letra y sentido de la norma constitucional. En lo sucesivo, o bien se 
Esta revista forma parte del acervo de la Biblioteca Jurídica Virtual del Instituto de Investigaciones Jurídicas de la UNAM

debe ampliar en la ley el tipo de campañas institucionales permitidas, o el criterio del IFE debe revisarse.

Es recomendable que en una futura reforma se precise con mayor detalle lo que debe entenderse por campañas de comunicación de servicios educativos, de salud, o las necesarias para la protección civil en casos de emergencia. Por otra parte, la autorización de numerosas excepciones da lugar a un excesivo gasto público en los medios de comunicación electrónicos. Al respecto, parece necesario definir en la legislación que, cuando se autoricen excepciones, las campañas institucionales deberán desplegarse dentro de los tiempos del Estado exclusivamente. Es decir, debería cederse parte del tiempo que hasta hoy ha utilizado el IFE para sus propios fines, de forma tal que las campañas de educación, de salud o de protección civil no signifiquen un gasto con cargo al erario, si bien el IFE ha de permanecer como administrador único de los tiempos del Estado durante los procesos electorales. No hacer ese cambio implicará que, como ocurrió en las campañas de 2012, toda autorización de una excepción para difundir mensajes gubernamentales se traduzca en una autorización de gasto.

\section{Entrevistas realizadas a actores clave en el diseño e implementación de la reforma electoral de 2007-2008 en materia de radio y televisión}

En la planeación de nuestro estudio consideramos la realización de entrevistas directas con los legisladores y dirigentes partidistas que participaron en la elaboración de las iniciativas y dictámenes durante el proceso de reforma electoral de 2007-2008. De igual forma, se programaron entrevistas para conocer la evaluación de la experiencia en la reglamentación y operación del modelo por ex consejeros y consejeros en funciones, del Consejo General del IFE, así como magistrados de la Sala Superior del TEPJF y especialistas en comunicación política. Sin embargo, por diferentes razones, no fue posible concretar la totalidad de las entrevistas programadas, por lo que las opiniones de quienes sí respondieron a nuestras preguntas constituyen un universo menor del originalmente planeado.

De esas valoraciones y opiniones destacamos la coincidencia en una positiva evaluación de los resultados de la aplicación del modelo, y 
Esta revista forma parte del acervo de la Biblioteca Jurídica Virtual del Instituto de Investigaciones Jurídicas de la UNAM

también en ubicar como su mayor debilidad el uso y abuso de los mensajes de 30 segundos, que dan lugar al fenómeno de la "spotización", justo uno de los efectos perniciosos del marco legal previo a la reforma electoral de 2007. Cabe recordar que en los dictámenes de la reforma constitucional (2007) de manera explícita los legisladores señalaron que la adopción de patrones de propaganda mercantil en las campañas electorales era una práctica que dañaba la calidad de la democracia mexicana y distanciaba a la ciudadanía de los partidos políticos y de los procesos electorales. Todos los entrevistados coinciden en recomendar una revisión de fondo en el uso del tiempo en radio y televisión por los partidos políticos, a fin de reducir significativamente el número de mensajes (spots) de 30 segundos para dar entrada a la difusión de mensajes "programáticos" con duración de entre tres y cinco minutos continuos, así como a la producción y transmisión de programas de mayor duración por las autoridades electorales, de manera que se fomente la difusión y conocimiento del sistema electoral, de los valores democráticos, y se promueva una ciudadanía mejor informada.

De igual forma, varios de los entrevistados coinciden en sugerir la apertura de espacios en televisión y radio para la difusión de debates entre candidatos a diputados y senadores, así como un mayor número de debates entre candidatos presidenciales, con formatos menos rígidos que los observados en 2012. Solamente en un caso encontramos la sugerencia de considerar una reforma constitucional que permita la compra de tiempo en radio y televisión por los partidos políticos, con limitaciones en cuanto al número de mensajes que podrían ser comprados y al gasto que se podría destinar a ese propósito.

Vale aclarar que dicha sugerencia no implica, para su autor, la supresión del modelo creado en 2007-2008, sino un complemento. Finalmente, de las entrevistas realizadas es destacable la coincidencia en la positiva evaluación de las capacidades técnico-operativas que el IFE pudo desarrollar y poner en práctica, en plazos breves y con resultados comprobados en cumplimiento de las pautas. La perspectiva de nuevas reformas legales que contribuyan a consolidar y fortalecer el modelo de acceso a radio y televisión es compartida por todos los entrevistados. 


\section{La polémica en torno a la reforma}

Durante el proceso de la reforma electoral de 2007-2008 se suscitó una polémica fundamental por las posturas de la Cámara Nacional de la Industria de Radio y Televisión (CIRT), aunque no fue la única, debido a aquello que los concesionarios y sus comunicadores consideraron "riesgos para la libertad de expresión de la ciudadanía y los periodistas". Aunque desde el Senado se recordó a los representantes de los medios electrónicos que los trabajos legislativos habían sido producto de una amplia consulta, la Junta de Coordinación Política aceptó la solicitud de la CIRT para ser escuchada, lo que dio pie a la muy difundida y comentada audiencia pública del 11 de septiembre de 2007, organizada en las instalaciones del Senado, donde dialogaron ríspidamente representantes de la CIRT y varios conductores de noticieros de radio y televisión con los senadores integrantes de las comisiones dictaminadoras. Al salir de dicha audiencia, tanto la CIRT como los concesionarios exigieron la realización de una consulta popular (figura no prevista por la ley) pues, a su parecer y según sus intereses, la reforma electoral era "regresiva y autoritaria" y no debía aprobarse sin la "participación del pueblo mexicano".

El debate sobre los supuestos riesgos para la libertad de expresión ha proseguido. Como muestra, en un desplegado publicado el 12 de febrero de 2012, la CIRT volvió a criticar duramente la reforma so pretexto de una serie de resoluciones y fallos del IFE y el TEPJF que, a su juicio, eran tan graves que ameritaban que el organismo acudiera a instancias internacionales para defender la libertad de expresión. En contraste, especialistas, académicos y periodistas de otros medios han brindado su apoyo a la reforma; entre otros, los ex consejeros del IFE José Woldenberg y Mauricio Merino celebraron la decisión, "frente a la ofensiva de las empresas que tienen las concesiones de la radio y la televisión". Sobre este tema hubo también expresiones vertidas por los candidatos presidenciales de la contienda de 2012, poniendo en tela de juicio ciertos aspectos de la reforma.

Ello vino a sumarse al clima de desconfianza sembrado entre los actores involucrados, $\mathrm{y}$, concluimos, hace previsible que el nuevo debate sobre el modelo vuelva a polarizarse. Los concesionarios privados de radio y televisión perdieron el poder de que disfrutaban para 
Esta revista forma parte del acervo de la Biblioteca Jurídica Virtual del Instituto de Investigaciones Jurídicas de la UNAM

beneficiar a candidatos y partidos. El modelo de acceso a esos medios, creado por la reforma de 2007-2008, cerró de golpe la puerta para que ese poder siguiera influyendo en los resultados electorales y en las decisiones de gobierno. Ese "poder fáctico" mantiene espacios y formas para influir en el electorado, pero ahora enfrenta un marco constitucional, legal y reglamentario, que permite evitar, detectar y sancionar abusos mediáticos; también enfrenta instituciones electorales fortalecidas y a una ciudadanía más consciente de sus derechos. 